\title{
Chronic Cadmium Exposure Aggravates the Cardiac Dysfunction in Type 2 Diabetic Mice by Promoting Inflammation and Fibrosis
}

Xiuxiu Liu

Soochow University https://orcid.org/0000-0003-0106-2847

\section{Shuai Wang}

The Shishan Community Hospital of SND in Suzhou

Mengyang Li

Soochow University

Jiafu Li

Soochow University

\section{Zhijie Sheng}

The Fifth People's Hospital of Suzhou

Jie zhang

Soochow University

zengli zhang ( $\nabla$ zhangzengli@suda.edu.cn )

Soochow University https://orcid.org/0000-0002-0108-0263

Original investigation

Keywords: Cd, Type 2 diabetes, Cardiac function, Fibrosis, Inflammation

Posted Date: June 25th, 2021

DOI: https://doi.org/10.21203/rs.3.rs-639901/v1

License: (9) (i) This work is licensed under a Creative Commons Attribution 4.0 International License.

Read Full License 


\section{Abstract}

Background: Diabetic cardiomyopathy (DCM) is a serious diabetic complication with high mortality. Cadmium (Cd) is a ubiquitous environmental contaminant and plays an important role in cardiac lesions. However, whether Cd aggravates DCM is debatable. In the present study, the effects of chronic Cd exposure on cardiomyopathy in normal and type 2 diabetic mice were investigated.

Methods: Sixty male C57BL/6J mice were randomly divided into four groups: blank control (normal mice without $\mathrm{Cd}$ exposure), $\mathrm{Cd}$ control (normal mice with Cd exposure, exposure level 1.74-2.45 mg/kg/day), diabetic mice control (diabetic mice without Cd exposure) and experimental group (diabetic mice with $\mathrm{Cd}$ exposure, exposure level 1.37-3.58 mg/kg/day). After 16 weeks Cd exposure, echocardiography was performed to determine cardiac structure and function. Other outcomes measures included myocardial injury, inflammation and fibrosis.

Results: Cd damaged the cardiac function by decreased $\mathrm{EF} \%$ (ejection fraction) and FS\% (fractional shortening) and increased concentration of cTnT (cardiac troponin T) and the expressions of BNP (brain natriuretic peptide) and ANP (atrial natriuretic peptide) in normal mice. For experimental group, the expression of IL-1 (Interleukin-1), TNF-a (tumor necrosis factor-alpha), MCP-1 (monocyte chemotactic protein 1), FN (fibronectin) and TGF- $\beta 1$ (transforming growth factor- $\beta 1$ ) were significantly increased, indicating that $\mathrm{Cd}$ promoted the accumulations of fibrosis and inflammation in diabetic mice. In terms of cardiac function, compared with normal mice, the cardiac injury marker of experimental mice was increased and the myocardial contractility was further attenuate, suggesting diabetic mice were more sensitive than normal mice when exposed to cadmium.

Conclusion: $\mathrm{Cd}$ could damage the heart contractility and aggravate the disruption of cardiac function in diabetic mice by deteriorating inflammation and fibrosis.

\section{Introduction}

Diabetes is one of the most prevalent and fasted growing disease worldwide, and is the seventh leading cause of death, with a mortality rate of 82.4 per $1000,000[1-3]$. The chronic diabetes complications are widely occurred in diabetic patients (macrovascular and microvascular system), which are the leading causes of mortality in diabetic patients[3]. Diabetic cardiomyopathy (DCM) is one of famous chronic diabetes complications[4]. Previous studies showed that hyperglycemia plays an important role in DCM development by aggravating myocardial fibrosis and collagen deposition[5]. Fibrosis contributes to impairment of systolic and diastolic function in heart, which lead to the development of ventricular dilation and systolic failure[6, 7]. Cardiac hypertrophy or ventricular dilation is compensated to keep pump strongly, while with the development of cardiopathy, the compensation will gradually turn into decompensation[8].

Cadmium (Cd) is a naturally occurring rare element, which dispersed into the environment through 
distance and eventually fall to the soil and water, and further enriched in animals and plants, which makes diet as a primary source of exposure among nonsmoking and nonoccupational population $[9,10]$. The daily intake of cadmium through diet is different in various countries which is depending on their pollution. For general Chinese population, the mean dietary Cd exposure was $15.3 \mu \mathrm{g} / \mathrm{kg} / \mathrm{month}$. However, in high consumer group (P95), the exposure level of Cd is up to $33.0 \mu \mathrm{g} / \mathrm{kg} / \mathrm{month}$, which is about 1.3 times of the provisional tolerable month intake[11]. The highest daily exposure of Cd was occurred in Thailand, in which the Cd exposure level was up to $3 \mu \mathrm{g} / \mathrm{kg} /$ day[12]. Tobacco smoking is another significant source of human Cd exposure, duo to higher concentration Cd presented in tobacco $(0.28-5.79 \mu \mathrm{g} / \mathrm{g})[13,14]$. During smoking, approximately $10-20 \%$ of the $\mathrm{Cd}$ will be absorbed in the lungs[15-17], which will be accumulated in the liver and the kidney, with a very long biological half-time ranging from 10 to 30 years [11]. Previous toxicological studies proved that the accumulated Cd could induce severe damage to various organs such as renal dysfunction, osteoporosis, fractures and cardiovascular disease (CVD) $[5,10,18,19]$. A large study found that Cd exposure is associated with increased risk of heart failure[20]. Experimental studies indicated that $\mathrm{Cd}$ damages the cardiomyocyte directly and regulate the mechanism of myocardial contractility[21, 22]. In addition, epidemiological studies suggested that higher $\mathrm{Cd}$ exposure is associated with an increased prevalence of diabetes [23, 24]. Previous studies indicated that $\mathrm{Cd}$ exposure increased gluconeogenesis, altered glucose transport and disruption of pancreatic islet function, which induced diabetes[25-27]. However, few papers reported that the influence of Cd exposure on the DCM, and the pathway and mechanism of Cd aggravated DCM is not clear. Thus, it is necessary to explore the relationship between $\mathrm{Cd}$ exposure and developments of diabetic cardiopathy.

In this study, the influences of Cd on DCM were analyzed using four groups of experiments including blank control (milli-Q water), Cd control (average exposure level $1.98 \mathrm{mg} / \mathrm{kg} /$ day), diabetic mice control (diabetic mice without $\mathrm{Cd}$ exposure) and experimental group (diabetic mice with average $\mathrm{Cd}$ exposure level $2.23 \mathrm{mg} / \mathrm{kg} /$ day). Echocardiography was used to calculate $\mathrm{EF} \%$ and $\mathrm{FS} \%$ to investigate the structural alterations in the cardiac. ANP (atrial natriuretic peptide), BNP (brain natriuretic peptide), $\beta-M H C$ (beta-myosin heavy chain) and cTnT (cardiac troponin T) were detected to explore the cardiac function. The expression level of FN (fibronectin) and TGF- $\beta 1$ (transforming growth factor- $\beta 1$ ) in tissues, along with staining were used to evaluate the extent of cardiac fibrosis. PCR (polymerase chain reaction) was used to measure the inflammation by the expression IL-1(Interleukin-1), TNF-a(tumor necrosis factoralpha) and MCP-1(monocyte chemotactic protein 1). This study aimed help to unravel some associations with $\mathrm{Cd}$ exposure and CVD in diabetics.

\section{Materials And Methods}

\subsection{Animals and experimental design}

Sixty male C57BL/6J mice (aged 3-5 weeks) were obtained from the Shanghai SLAC Laboratory Animal Company Limited. Before the experiment, animals were acclimatized to laboratory condition for a week.

Loading [MathJax]/jax/output/CommonHTML/jax.js r groups: the blank control group, Cd control group, DM 
control group, and experimental group. The daily Cd exposure of normal human being is about 1-3 $\mu \mathrm{g} / \mathrm{kg} / \mathrm{day}$, and the safety factor in risk assessment is 100-1000[28]. A middle higher exposure level (about $2 \mathrm{mg} / \mathrm{kg} /$ day) was selected to represent most of situations using $155 \mathrm{ppm}$ Cd drinking water (cadmium chloride), which represented all exposure pathways of $\mathrm{Cd}$. The exposure was performed for 16 weeks. The type 2 diabetes mellitus was induced by a single intraperitoneal injection of $100 \mathrm{mg} / \mathrm{kg} \mathrm{STZ}$ (streptozotocin) after 8 weeks high-fat diets (D12492). When the fasting blood glucose concentration of mice was higher than $16.7 \mathrm{mmol} / \mathrm{L}$ after one week of diabetic induction, the mice were considered as successful diabetic mice. The blank control and Cd control group mice were treated with normal diets, while the diabetic control and experimental mice were treated with high-fat diets continuously[29]. At the end of experiment, animals were sacrificed after overnight fasting. Cardiac tissues and blood were collected and processed for further experiments.

\subsection{Echocardiography}

Transthoracic echocardiography was performed with an ultrasound machine (Vevo2100, Visual Sonics, Canada). Briefly, mice were anesthetized with inhaled isoflurane $(1.5 \mathrm{~L} / \mathrm{min})$. Once sedated, the mouse was secured onto the echocardiography platform with tape. And then, the chest hair of mouse was removed, and the ultrasound gel was place on the chest. An ultrasound probe was used to image the mouse heart. During the process, the left ventricular (LV) systolic diameter, LV diastolic diameter, LV ejection fraction (EF\%), and LV fractional shortening (FS\%) were measured and calculated. After the experiment, the mice were return to the cages and monitored until recovered spontaneous body movements.

\subsection{Myocardial cellular injury detection}

cTnT was measured by an ELISA kit according to the instructions of the manufacturer (E-EL-M1801c, Elabscience, Biotechnology Co., Ltd). After sacrificed, blood samples of mice were collected and centrifuged at $3000 \mathrm{rpm}$ for 10 minutes, and then the supernatant was transferred to Eppendorf tube and was stored at $-20^{\circ} \mathrm{C}$ until measurement. During measurement, $100 \mu \mathrm{l}$ of serum and reference standard were added into ELISA plate respectively and incubated at $37^{\circ} \mathrm{C}$ for $90 \mathrm{~min}$. Then, the ELISA plate was washed three times by washing buffer. After that, $100 \mu$ l of HRP (horseradish peroxidase) conjugate was incubated for $30 \mathrm{~min}$ at $37^{\circ} \mathrm{C}$. The mixture was washed for five times and $90 \mu \mathrm{TMB}\left(3,3^{\prime}, 5,5^{\prime}-\right.$

Tetramethylbenzidine) was added. After $15 \mathrm{~min}$ incubation, $50 \mu \mathrm{l}$ stop solution was added and cTnT was measured at $450 \mathrm{~nm}$.

\subsection{Quantitative Real-Time-PCR}

Total RNA was extracted from the hearts using Trizol according to the manufacturer's instructions. Complementary deoxyribonucleic acid (CDNA) was synthesized from 500 ng total RNA using a reverse transcription kit (Hifair® II 1st Strand cDNA Synthesis SuperMix, YEASEN, Shanghai, China) according to the manufacturer's protocol. PCRs were performed using the Applied Biosystems 7500 Real-time PCR Systems and Hieff ${ }^{T M}$ qPCR SYBR® GREEN Master Mix kit (YEASEN, Shanghai, China). The PCR was 
and annealed at $60^{\circ} \mathrm{C}$ for $30 \mathrm{~s}$. The melting curve phase followed the default settings of the instrument. The primers were synthesized by Genscript. The sequences of the primers are shown in Table 1.

Table 1

The sequences of the primers.

\begin{tabular}{|lll|}
\hline Gene & Forward & Reverse \\
\hline GAPDH & 5'-ACTCCACTCACGGCAAATTC-3' & 5'-TCTCCATGGTGGTGAAGACA-3' \\
\hline TGF $\beta$ & 5'-ATCCTGTCCAAACTAAGGCTCG-3' & 5'-ACCTCTTTAGCATAGTAGTCCGC-3' \\
\hline MCP1 & 5'-TAAAAAACCTGGATCGGAACCAAA-3' & 5'-GCATTAGCTTCAGATTTACGGGT-3' \\
\hline IL1 & 5'-CCGTGGACCTTCCAGGATGA-3' & 5'-GGGAACGTCACACACCAGCA-3' \\
\hline TNFa & 5'-TGGAACTGGCAGAAGAGG-3' & 5'-AGACAGAAGAGCGTGGTG-3' \\
\hline BMHC & 5'-CCGAGTCCCAGGTCAACAA-3' & 5'-CTTCACGGGCACCCTTGGA-3' \\
\hline TGFB1 & 5'-ATGGTGGACCGCAACAAC-3' & 5'-CCAAGGTAACGCCAGGAA-3' \\
\hline FN & 5'-CCGGTGGCTGTCAGTCAGA-3' & 5'-CCGTTCCCACTGCTGATTTATC-3' \\
\hline ANP & 5'-CGTGCCCCGACCCACGCCAGCATGG-3' & 5'-GCCTCCGAGGGCCAGCGAGCAGAGC-3' \\
\hline BNP & 5'-GAGGTCACTCCTATCCTCTGG-3' & 5'-GCCATTTCCTCCGACTTTTCTC-3' \\
\hline
\end{tabular}

\subsection{Histopathology}

The myocardial tissues were performed with hematoxylin-eosin (HE) staining to examine histopathology. The heart samples were put in $10 \%$ paraformaldehyde solution more than $72 \mathrm{~h}$, dehydrated in xylene gradient, embedded in paraffin and cut down into slices. Then the samples were stained with hematoxylin and eosin after taking off paraffin. Finally, the slices were observed under a light microscope (Leica, Germany).

\subsection{Masson staining}

Mice cardiac tissues were fixed and embedded in paraffin, then sliced into section with a microtome ((Leica, Germany). Masson trichrome (G1340, Solarbio, Beijing, China) to evaluate the fibrosis and the extent of extracellular matrix deposition. Weigert iron hematoxylin solution was used to dye for 7 minutes and the sections were stained with ponceau-acid fuchsin for $8 \mathrm{~min}$. Then, the slices were washed in weak acid and differentiated in phosphomolybdic acid for $2 \mathrm{~min}$. The sections were stained with aniline blue dye solution for 2 min directly and then dehydrated with ethanol series, cleared with xylene. Finally, the sections were observed under a light microscope.

\subsection{Statistical Analysis}


The data analysis and graphs were performed with GraphPad Prism 8.0 software. Data were presented as mean \pm standard deviation. One-way analysis of variance followed by the Bonferroni post-test was used for analysis. The difference at $P \otimes 0.05$ was considered as statistically significant.

\section{Results And Discussion}

\subsection{Daily drinking water and Cd intake}

The daily drinking water ingestion rates of four groups of mice are shown in Fig. 1A. As shown in Fig. 1A, the water ingestion rates for blank control and $\mathrm{Cd}$ control mice (normal mice) looked stable during 25 weeks with a mean of $0.115 \mathrm{~mL} / \mathrm{g}$ body weight/day, whose water ingestion rates showed a slight decrease in first 12 weeks and kept stable in following time. However, the water ingestion rates for diabetic control and experimental mice (diabetic mice) were not stable. For diabetic control mice, the water ingestion rate was slightly decreased in first four weeks (from $0.1 \mathrm{~mL} / \mathrm{g}$ body weight/day to 0.077 $\mathrm{mL} / \mathrm{g}$ body weight/day), and increased from $0.077 \mathrm{~mL} / \mathrm{g}$ body weight/day to $0.32 \mathrm{~mL} / \mathrm{g}$ body weight/day during 4-12nd weeks, and kept stable in the last 12 weeks. For experimental mice, the regulation is same to diabetic control mice in the early exposure time, whose water ingestion rate also showed a slight decrease in the first 4 weeks, and had a great increase from 4 nd to 12 nd weeks. However, unlike diabetic control mice, water ingestion rate of experimental mice showed an obvious decrease in the last time (1224 weeks), indicating $\mathrm{Cd}$ exposure decreased the drinking water ingestion of diabetic mice. However, this phenomenon not occurred in normal mice, meaning diabetic mice might be more sensitive than normal mice during Cd exposure. In addition, the average water ingestion rate of diabetic mice was higher than normal mice. There are several reasons for above phenomenon. The $\mathrm{Cd}$ exposure level is calculated by daily water consumption and body weight. Thus, first reason is diabetic mice tend to drink more water than normal mice, and second is that diabetic mice have lower body weight. At the beginning of the study, the body weight had no significant difference between $\mathrm{Cd}$ control and experimental group mice. After injection of STZ, the weight of diabetic mice gradually decreased. Finally, for the reason of decreased cadmium exposure in the last time is still unclear, previous study found the similar phenomenon that the average intake of the cadmium in the early phase of treatment was higher than that in the subsequent[30].

For daily Cd exposure, blank and diabetic control mice were negligible due to without Cd in drinking water. For Cd control and experimental mice, the regulation of daily Cd exposure level is same to drinking water ingestion rate. The daily $\mathrm{Cd}$ exposure levels of $\mathrm{Cd}$ control and experimental group were 1.74-2.45 and $1.37-3.58 \mathrm{mg} / \mathrm{kg}$ body weight/day respectively, the level has been translated from mice to human being.

\subsection{Cd aggravated the diabetes-induced injury of cardiac function}

Defective cardiac contractility is one of the characteristic abnormalities of diabetic cardiomyopathy. Echocardioaraphic imaaina is used to assess the cardiac physiology and architecture. It could effectively Loading [MathJax]/jax/output/CommonHTML/jax.js 
calculate the EF\% and then detected cardiac contractility, which is closely related to cardiac function [31, 32]. Hence, we used echocardiographic imaging to examine the impact of chronic $\mathrm{Cd}$ exposure on heart function. As shown in Fig. 2 and Table 2, the EF\% and FS\% of mice in experimental, diabetic control and $\mathrm{Cd}$ control group were significantly lower than blank control $(P<0.05)$, and the lowest value occurred in experimental group. Due to diabetic cardiomyopathy is consist of two major components: (1) physiological adaptation to metabolic alterations shortly; (2) the capacity of myocardium for repair is limited and lead to degenerative changes $[33,34]$. In early stage of DCM, overt functional abnormalities were not happened, and ejection fraction was normal in myocytes. With the development of disease, myocyte apoptosis and necrosis were increased, resulting in myocyte injury and myocardial fibrosis, which caused a slight decrease of $\mathrm{EF} \%$, while the obvious changes in cardiac structure and function will gradually show after that[33].

Table 2

Echocardiographic assessment of left ventricle structural and functional data in mice

\begin{tabular}{|c|c|c|c|c|}
\hline & Blank Control & Cd Control & DM Control & Experiment \\
\hline $\mathrm{EF}(\%)$ & $57.39 \pm 3.76$ & $46.84 \pm 5.35$ ** & 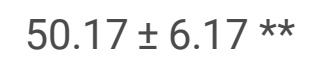 & $44.46 \pm 6.27 * \star \star$ \\
\hline $\mathrm{FS}(\%)$ & $29.59 \pm 2.46$ & $23.13 \pm 3.13$ ** & $25.19 \pm 3.78$ ** & $21.65 \pm 3.63 * \star \star$ \\
\hline LVID;d(mm) & $3.70 \pm 0.27$ & $3.96 \pm 0.39$ & $3.94 \pm 0.22$ & $3.73 \pm 0.34$ \\
\hline LVID;s(mm) & $2.61 \pm 0.22$ & $3.04 \pm 0.36$ * & $2.95 \pm 0.24^{\star}$ & $2.93 \pm 0.32^{\star}$ \\
\hline LVAW;d(mm) & $0.74 \pm 0.09$ & $0.76 \pm 0.15$ & $0.68 \pm 0.10$ & $0.66 \pm 0.09$ \\
\hline LVAW;s(mm) & $0.99 \pm 0.07$ & $0.95 \pm 0.15$ & $0.90 \pm 0.11$ & $0.82 \pm 0.09 * \&$ \\
\hline LVPW;d(mm) & $0.74 \pm 0.08$ & $0.74 \pm 0.09$ & $0.76 \pm 0.05$ & $0.61 \pm 0.06 * \star \star \& \& \& \$ \$ \$$ \\
\hline LVPW;s(mm) & $0.98 \pm 0.14$ & $0.96 \pm 0.11$ & $1.02 \pm 0.06$ & $0.84 \pm 0.05^{*} \& \$ \$ \$$ \\
\hline LV Vol;d( $\mu \mathrm{L})$ & $58.48 \pm 10.00$ & $69.07 \pm 15.37$ & $67.70 \pm 9.38$ & $59.97 \pm 13.02$ \\
\hline LV Vol;s( $\mu \mathrm{L})$ & $25.00 \pm 5.47$ & $36.97 \pm 10.02$ * & $33.80 \pm 6.68 *$ & $33.48 \pm 9.08 *$ \\
\hline LV mass $(\mathrm{mg})$ & $75.02 \pm 14.08$ & $85.16 \pm 21.30$ & $80.26 \pm 9.94$ & $62.05 \pm 8.32 \& \& \$$ \\
\hline LVM/BW & 0.00248 & 0.00270 & 0.00311 & 0.00276 \\
\hline \multicolumn{5}{|c|}{$\begin{array}{l}\text { Data are presented as the mean } \pm \text { SD. EF: ejection fraction; FS: fractional shortening; LV: left } \\
\text { ventricular; LVIDd: LV internal diastolic diameter; LVIDs: LV internal systolic diameter; LVAW;d: End- } \\
\text { diastole LV anterior wall thickness; LVAWs: End-systolic LV anterior wall thickness; LVPWd: End- } \\
\text { diastole LV posterior wall thickness; LVPWs: End-systolic LV posterior wall thickness; LV Vold: LV end- } \\
\text { diastolic volume; LV Vols: LV end-systolic volume; LVM: LV mass; BW: body weight. “*, ** and ***” } \\
\text { meaning the } P \text { value lower than } 0.05,0.01 \text { and } 0.001 \text { respectively (compared with blank control). \& } P< \\
0.05, \& \& P<0.01, \& \& \& P<0.001 \text { (compared with Cd control); } \$ P<0.05, \$ \$ P<0.01 \text {, } \$ \$ \$ P<0.001 \\
\text { (compared with group diabetic mice (DM) control). }\end{array}$} \\
\hline
\end{tabular}

In addition, echocardiographic data showed that the left ventricular wall thickness had no significant Loading [MathJax]/jax/output/CommonHTML/jax.js t and diabetes increased LV mass (LVM)/body weight (BW) 
ratio of mice. The lower ejection fraction and higher LVM/BW in Cd control and diabetic control group indicated that the heart was overburdened and the myocardium compensates were enlarged and hypertrophied to overcome the increased resistance, which ensure the ejection volume and maintain the normal cardiac output for a long time[35]. Meanwhile, compared with diabetic control group, the LVM/BW ratio and $\mathrm{EF} \%$ of mice was decreased in experimental group $(p<0.05)$ which means the metabolic alteration is overburdened and Cd aggravates cardiac dysfunction and exceeds stage of DCM in diabetic mice.

\subsection{Cd increased the level of fibrosis and cardiac injury in diabetic mice}

To explore the mechanism of Cd-induced cardiac dysfunction, HE staining, the cTnT, $B N P, A N P$ and $\beta$ $M H C$ of mice were measured. In general, for normal mice, $C d$ increased the mRNA levels of $A N P$ and $B N P$ and the serum concentrations of cTnT (Fig. 3). As shown in Fig. 3, the cTnT content of experimental group mice was two times higher than diabetic control group mice, but the mRNA expression level of $B N P$ and $\beta-M H C$ were decreased (Fig. 3). CTnT is a specific marker for cardiac injury and it is regarded as more sensitive and specific than other cardiac biomarkers[36]. After myocardial injury, cTnT is released from death cell within 2-4 $\mathrm{h}$ and remained in the blood stream probably more than 10 days[37]. In this study, we found that $\mathrm{Cd}$ increased the CTnT concentration in diabetic and normal mice, which suggested that $\mathrm{Cd}$ could damage the myocardium and aggravated the cardiac injury in diabetic mice. HE staining showed the degree of myocardial tissue impairment in mice models (Fig. 4A), and the myocardial cells were disordered and destroyed in $\mathrm{Cd}$ control and DM control group. For experimental group, the morphology of cardiomyocytes was further damaged and there was obvious rupture.

$\beta-\mathrm{MHC}$ and BNP are two significant hypertrophy markers. Once cardiomyocytes become stretched in response to mechanical strain, BNP would be largely synthesized and secreted by ventricular myocytes, which associated with overloaded pressure and ventricular volume expansion [38]. And in current guidelines, the increase of plasma BNP level is in proportion to disease severity in patients with heart failure and cardiac dysfunction which is different with the results in present study[39, 40]. For this, we supposed two possible reasons. At first, fibrosis could deposit extra cellular matrix (ECM) and leads to stiffness of ventricular wall, which blocked the stretching of cardiomyocytes [41]. In this study, the myocardial sections were dyed with Masson staining and the myocardial collagen fibers were stained blue, and the myocardial fibers were stained red. As shown in Fig. 4B, Cd and DM deposited amounts of collagen when compared with blank group. For diabetic mice, cadmium disordered the arrangement of myocardial fibers and accelerated the fibrosis on myocardial fibers. Furthermore, $\mathrm{Cd}$ and diabetes increased the level of TGF- $\beta 1$, while mRNA level of $F N$ almost unchanged. And the mRNA expressions of $T G F-\beta$ and $F N$ in experimental mice were approximately two times higher than that in diabetic control mice. This phenomenon might be due to that with the development of cardiopathy, accumulated fibrosis inhibited cardiomyocytes stretching, and then blocked the secretion of BNP. Besides this conjecture, previous study suggested that the mRNA expression levels of $A N P, B N P$ and $\beta-M H C$ were different in 
clearly based on the measured mRNA expression of $A N P, B N P$ and $\beta-M H C$. Further investigation is required for elucidating the significant of $A N P, B N P$ and $\beta-M H C$ mRNA levels in cardiomyopathy.

\subsection{Cd increased the level of inflammatory cytokine in diabetic mice.}

With the development of cardiac disease, the inflammatory cytokine response would be activated and result in continuous deleterious effects on the heart and vasculature, finally lead to the progression of cardiac dysfunction and heart failure[43]. Thus, the mRNA levels of TNF- $a$ (tumor necrosis factor-alpha), IL-1 (Interleukin-1) and MCP-1 (monocyte chemotactic protein 1) were detected to investigate the effect of inflammatory cytokine on cardiac injury. MCP-1 plays a critical role in heart disease, it can recruit peripheral leucocytes to tissues and result in the development of chronic inflammation[43]. TNF-a could be produced by cardiac cells while they are in the situation of pressure and volume overload, which contributes to the progressive LV wall thinning and adverse cardiac remodeling[44]. In addition, TNF-a can increase the production of IL-1 and they exacerbates cardiac myocyte contractile dysfunction[44, 45]. As showed in Fig. 5, for normal mice, the expressions of TNF- $a$ and $I L-1$ were slightly increased, and the expression of $M C P-1$ was increased after $C d$ exposure. For diabetic mice, the mRNA expressions of TNFa, IL-1 and MCP-1 in experimental group were two-three times higher than the diabetic control mice. Inflammation is one of the earliest events in cardiac stress situations and involved in myocardial remodeling[46]. Ventricular remodeling contributes to ventricular dilation and dysfunction, which includes myocyte hypertrophy and extracellular matrix remodeling[47]. The constant remodeling of extracellular matrix is regulated by matrix metalloproteinases, which controlled by cytokines including TNF- $a$ and IL$1 \beta[48]$. As Fig. 5 showed, the diabetic mice were more sensitive than normal mice when exposed to Cd and showed severer inflammation and extracellular matrix remodeling (Fig. 4B). Additional, MCP-1 plays a causative role in experimental diabetic cardiopathy, and the heart failure was attenuated in MCP-1 deficient animal models [49-51]. These results suggested that Cd could promote myocardial inflammatory processes in diabetic mice, finally contributes to the adverse ventricular remodeling.

\section{Conclusion}

In the present study, a comprehensive study implemented to analyze the impact of Cd exposure on cardiac dysfunction of normal and diabetic mice. For normal mice, Cd could induce their cardiac injury by decreased the myocardial contractility. For diabetic mice, Cd exposure decreased their EF\% and FS\% and promoted fibrosis and inflammation. These results indicated that $\mathrm{Cd}$ exacerbates cardiopathy development of mice especially diabetic mice.

\section{Abbreviations}

DCM: diabetic cardiomyopathy 
EF: ejection fraction

FS: fractional shortening

cTnT: cardiac troponin T

BNP: brain natriuretic peptide

ANP: atrial natriuretic peptide

IL-1: Interleukin-1

TNF-a: tumor necrosis factor-alpha

MCP-1: monocyte chemotactic protein 1

FN: fibronectin

TGF- $\beta 1$ : transforming growth factor- $\beta 1$

CVD: cardiovascular disease

PCR: polymerase chain reaction

STZ: streptozotocin

LV囚left ventricular

HRP: horseradish peroxidase

TMB: 3,3',5,5'-Tetramethylbenzidine

cDNA: Complementary deoxyribonucleic acid

HE囚hematoxylin-eosin

LVM『left ventricular mass

BW: body weight

\section{Declarations}

\subsection{Ethics approval}

This study followed the Guide for the Care and Use of Laboratory Animals, and the protocols were approved by the Soochow University Institutional Animal Care and Use Committee (201903A156). 


\subsection{Consent for publication}

Not applicable

\subsection{Availability of data and materials}

All data and materials are available upon request.

\subsection{Competing interests}

The authors declare that they have no competing interests.

\subsection{Funding}

This research was supported by the National Natural Scientific Funding of China (No.81773414, No.81673151) and a project funded by Priority Academic Program Development of Jiangsu Higher Education Institutions (PAPD).

\subsection{Authors' contributions}

SW, XXL and ZLZ participated in research design; XXL, SW, MYL and SZJ conducted experiments; XXL and SW performed data analysis and interpretation; XXL writing the manuscript and JFL, ZLZ and MYL critically revised the manuscript. All authors read and approved the final manuscript.

\subsection{Acknowledgements}

Not applicable.

\section{References}

1. Glovaci D, Fan W, Wong ND. Epidemiology of Diabetes Mellitus and Cardiovascular Disease. Curr Cardiol Rep. 2019;21(4):21.

2. Cho NH, Shaw JE, Karuranga S, Huang Y, da Rocha Fernandes JD, Ohlrogge AW, Malanda B. IDF Diabetes Atlas: Global estimates of diabetes prevalence for 2017 and projections for 2045. Diabetes Res Clin Pract. 2018;138:271-81.

3. Cole JB, Florez JC. Genetics of diabetes mellitus and diabetes complications. Nature reviews Nephrology. 2020;16(7):377-90.

4. Lee WS, Kim J. Diabetic cardiomyopathy: where we are and where we are going. The Korean journal of internal medicine 2017, 32(3):404-421.

5. Aneja A, Tang WH, Bansilal S, Garcia MJ, Farkouh ME. Diabetic cardiomyopathy: insights into pathogenesis, diagnostic challenges, and therapeutic options. Am J Med. 2008;121(9):748-57.

6. Janicki JS, Brower GL. The role of myocardial fibrillar collagen in ventricular remodeling and 
7. Iwanaga Y, Aoyama T, Kihara Y, Onozawa Y, Yoneda T, Sasayama S. Excessive activation of matrix metalloproteinases coincides with left ventricular remodeling during transition from hypertrophy to heart failure in hypertensive rats. J Am Coll Cardiol. 2002;39(8):1384-91.

8. Dick SA, Epelman S. Chronic Heart Failure and Inflammation: What Do We Really Know? Circulation research. 2016;119(1):159-76.

9. Schaefer HR, Dennis S, Fitzpatrick S. Cadmium: Mitigation strategies to reduce dietary exposure. Journal of food science. 2020;85(2):260-7.

10. Satarug S, Garrett SH, Sens MA, Sens DA. Cadmium, environmental exposure, and health outcomes. Ciencia saude coletiva. 2011;16(5):2587-602.

11. Song Y, Wang Y, Mao W, Sui H, Yong L, Yang D, Jiang D, Zhang L. Dietary cadmium exposure assessment among the Chinese population. 2017, 12(5):e0177978.

12. Satarug S, Swaddiwudhipong W, Ruangyuttikarn W, Nishijo M, Ruiz P. Modeling cadmium exposures in low- and high-exposure areas in Thailand. Environmental health perspectives. 2013;121(5):531-6.

13. Prokopowicz A, Sobczak A, Szuła-Chraplewska M, Ochota P, Kośmider L. Exposure to Cadmium and Lead in Cigarette Smokers Who Switched to Electronic Cigarettes. Nicotine tobacco research: official journal of the Society for Research on Nicotine Tobacco. 2019;21(9):1198-205.

14. Ganguly K, Levänen B, Palmberg L, Åkesson A, Lindén A. Cadmium in tobacco smokers: a neglected link to lung disease? European respiratory review: an official journal of the European Respiratory Society 2018, 27(147).

15. Mezynska M, Brzóska MM. Environmental exposure to cadmium-a risk for health of the general population in industrialized countries and preventive strategies. Environ Sci Pollut Res Int. 2018;25(4):3211-32.

16. Ashraf MW: Levels of heavy metals in popular cigarette brands and exposure to these metals via smoking. TheScientificWorldJournal 2012, 2012:729430.

17. Galazyn-Sidorczuk M, Brzóska MM, Moniuszko-Jakoniuk J. Estimation of Polish cigarettes contamination with cadmium and lead, and exposure to these metals via smoking. Environ Monit Assess. 2008;137(1-3):481-93.

18. Edwards JR, Prozialeck WC. Cadmium, diabetes and chronic kidney disease. Toxicol Appl Pharmcol. 2009;238(3):289-93.

19. Tellez-Plaza M, Jones MR, Dominguez-Lucas A, Guallar E, Navas-Acien A. Cadmium exposure and clinical cardiovascular disease: a systematic review. Curr Atheroscler Rep. 2013;15(10):356.

20. Everett CJ, Frithsen IL. Association of urinary cadmium and myocardial infarction. Environmental research. 2008;106(2):284-6.

21. Turdi S, Sun W, Tan Y, Yang X, Cai L, Ren J. Inhibition of DNA methylation attenuates low-dose cadmium-induced cardiac contractile and intracellular $\mathrm{Ca}(2+)$ anomalies. Clin Exp Pharmacol Physiol. 2013;40(10):706-12. 
22. Protsenko YL, Klinova SV, Gerzen OP, Privalova LI, Minigalieva IA, Balakin AA, Lookin ON, Lisin RV, Butova KA, Nabiev SR, et al. Changes in rat myocardium contractility under subchronic intoxication with lead and cadmium salts administered alone or in combination. Toxicology reports. 2020;7:43342.

23. Li Y, Zhang Y, Wang W, Wu Y. Association of urinary cadmium with risk of diabetes: a meta-analysis. 2017, 24(11):10083-10090.

24. Wallia A, Allen NB, Badon S, El Muayed M. Association between urinary cadmium levels and prediabetes in the NHANES 2005-2010 population. Int J Hyg Environ Health. 2014;217(8):854-60.

25. Edwards J, Ackerman C. A Review of Diabetes Mellitus and Exposure to the Environmental Toxicant Cadmium with an Emphasis on Likely Mechanisms of Action. Curr Diabetes Rev. 2016;12(3):252-8.

26. Chapatwala KD, Boykin M, Butts A, Rajanna B. Effect of intraperitoneally injected cadmium on renal and hepatic gluconeogenic enzymes in rats. Drug chemical toxicology. 1982;5(3):305-17.

27. Han JC, Park SY, Hah BG, Choi GH, Kim YK, Kwon TH, Kim EK, Lachaal M, Jung CY, Lee W. Cadmium induces impaired glucose tolerance in rat by down-regulating GLUT4 expression in adipocytes. Arch Biochem Biophys. 2003;413(2):213-20.

28. Li J, Zhang Z, Ma L, Zhang Y, Niu Z. Implementation of USEPA RfD and SFO for improved risk assessment of organophosphate esters (organophosphate flame retardants and plasticizers). Environment international. 2018;114:21-6.

29. Riehle C, Bauersachs J. Of mice and men: models and mechanisms of diabetic cardiomyopathy. Basic Res Cardiol. 2018;114(1):2.

30. Brzóska MM, Majewska K, Moniuszko-Jakoniuk J. Mineral status and mechanical properties of lumbar spine of female rats chronically exposed to various levels of cadmium. Bone. 2004;34(3):517-26.

31. Baudouy D, Michiels JF, Vukolic A, Wagner KD, Wagner N. Echocardiographic and Histological Examination of Cardiac Morphology in the Mouse. Journal of visualized experiments: JoVE 2017(128).

32. Raher MJ, Thibault H, Poh KK, Liu R, Halpern EF, Derumeaux G, Ichinose F, Zapol WM, Bloch KD, Picard $\mathrm{MH}$, et al. In vivo characterization of murine myocardial perfusion with myocardial contrast echocardiography: validation and application in nitric oxide synthase 3 deficient mice. Circulation. 2007;116(11):1250-7.

33. Fang ZY, Prins JB, Marwick TH. Diabetic cardiomyopathy: evidence, mechanisms, and therapeutic implications. Endocr Rev. 2004;25(4):543-67.

34. Maisch B, Alter P, Pankuweit S: Diabetic cardiomyopathy-fact or fiction? Herz 2011, 36(2):102-115.

35. Han Q, Liu Q, Zhang H, Lu M, Wang H, Tang F, Zhang Y. Simvastatin Improves Cardiac Hypertrophy in Diabetic Rats by Attenuation of Oxidative Stress and Inflammation Induced by Calpain-1-Mediated Activation of Nuclear Factor-КB (NF-кB). Medical science monitor: international medical journal of experimental clinical research. 2019;25:1232-41. 
36. Fathil MF, Md Arshad MK, Gopinath SC, Hashim U, Adzhri R, Ayub RM, Ruslinda AR, Nuzaihan MNM, Azman AH, Zaki M, et al. Diagnostics on acute myocardial infarction: Cardiac troponin biomarkers. Biosens Bioelectron. 2015;70:209-20.

37. Burcu Bahadır E, Kemal Sezgintürk M. Applications of electrochemical immunosensors for early clinical diagnostics. Talanta. 2015;132:162-74.

38. Liang F, Atakilit A, Gardner DG. Integrin dependence of brain natriuretic peptide gene promoter activation by mechanical strain. J Biol Chem. 2000;275(27):20355-60.

39. Kuwahara K, Nakagawa Y, Nishikimi T. Cutting Edge of Brain Natriuretic Peptide (BNP) Research The Diversity of BNP Immunoreactivity and Its Clinical Relevance. Circulation journal: official journal of the Japanese Circulation Society. 2018;82(10):2455-61.

40. Cao Z, Jia Y, Zhu B. BNP and NT-proBNP as Diagnostic Biomarkers for Cardiac Dysfunction in Both Clinical and Forensic Medicine. 2019, 20(8).

41. Konstam MA, Kramer DG, Patel AR, Maron MS, Udelson JE. Left ventricular remodeling in heart failure: current concepts in clinical significance and assessment. JACC Cardiovascular imaging. 2011;4(1):98-108.

42. Thapa K, Wu KC, Sarma A, Grund EM, Szeto A, Mendez AJ, Gesta S, Vishnudas VK, Narain NR, Sarangarajan R. Dysregulation of the calcium handling protein, CCDC47, is associated with diabetic cardiomyopathy. 2018, 8:45.

43. Niu J, Kolattukudy PE. Role of MCP-1 in cardiovascular disease: molecular mechanisms and clinical implications. Clinical science (London England: 1979). 2009;117(3):95-109.

44. Hedayat M, Mahmoudi MJ, Rose NR, Rezaei N. Proinflammatory cytokines in heart failure: doubleedged swords. Heart Fail Rev. 2010;15(6):543-62.

45. Turner NA, Mughal RS, Warburton P, O'Regan DJ, Ball SG, Porter KE. Mechanism of TNFalphainduced IL-1alpha, IL-1 beta and IL- 6 expression in human cardiac fibroblasts: effects of statins and thiazolidinediones. Cardiovascular research. 2007;76(1):81-90.

46. Passino C, Barison A, Vergaro G, Gabutti A, Borrelli C, Emdin M, Clerico A. Markers of fibrosis, inflammation, and remodeling pathways in heart failure. Clin Chim Acta. 2015;443:29-38.

47. Li B, Liao YH, Cheng X, Ge H, Guo H, Wang M. Effects of carvedilol on cardiac cytokines expression and remodeling in rat with acute myocardial infarction. Int J Cardiol. 2006;111(2):247-55.

48. Li YY, McTiernan CF, Feldman AM. Interplay of matrix metalloproteinases, tissue inhibitors of metalloproteinases and their regulators in cardiac matrix remodeling. Cardiovascular research. 2000;46(2):214-24.

49. Wang XT, Gong Y, Zhou B, Yang JJ, Cheng Y, Zhao JG, Qi MY. Ursolic acid ameliorates oxidative stress, inflammation and fibrosis in diabetic cardiomyopathy rats. Biomedicine pharmacotherapy $=$ Biomedecine pharmacotherapie. 2018;97:1461-7.

50. Younce $\mathrm{CW}$, Wang K, Kolattukudy PE. Hyperglycaemia-induced cardiomyocyte death is mediated via MCP-1 production and induction of a novel zinc-finger protein MCPIP. Cardiovascular research. 
51. Manna P, Sil PC. Impaired redox signaling and mitochondrial uncoupling contributes vascular inflammation and cardiac dysfunction in type 1 diabetes: Protective role of arjunolic acid. Biochimie. 2012;94(3):786-97.

\section{Figures}
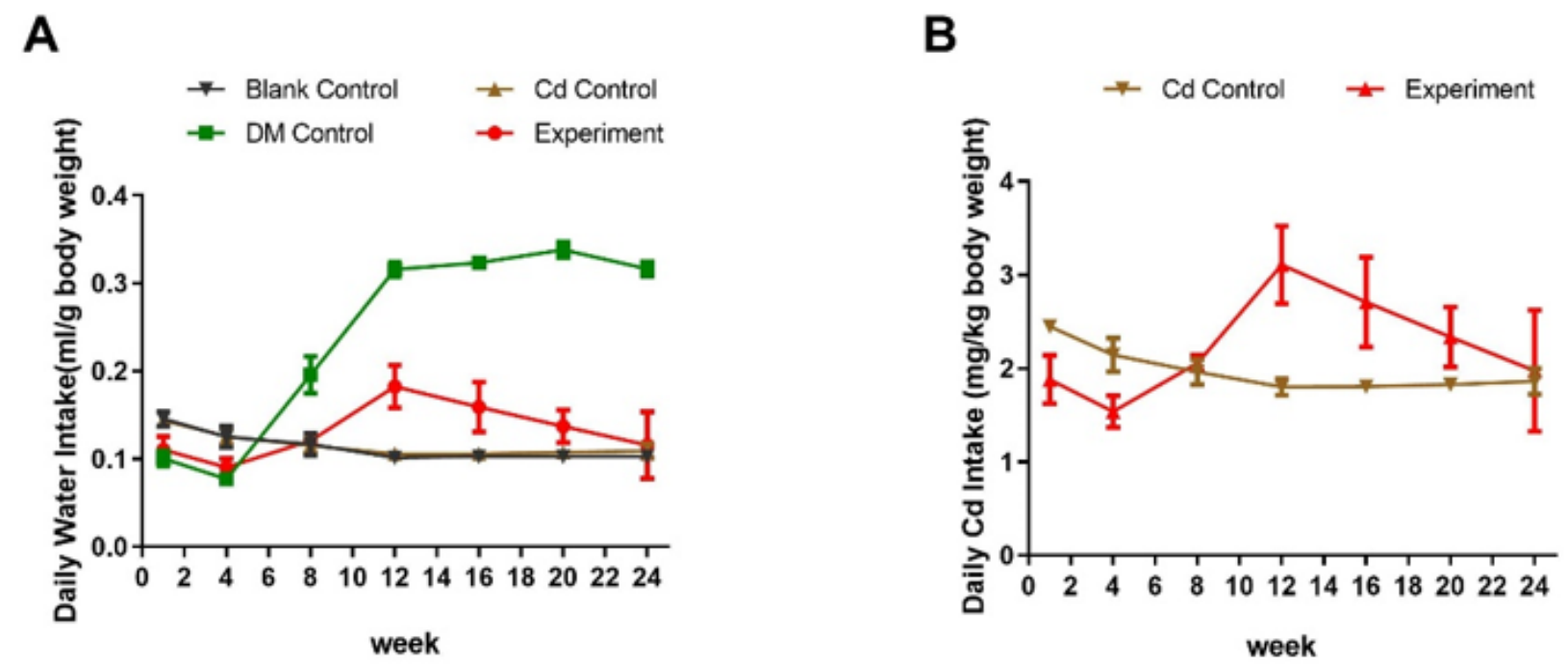

Figure 1

Drinking water and Cd intake of mice. (A) Drinking water; (B) Oral Cd exposure level Cd control group and experimental group, the exposure level has been translated from mice to human being. The Cd exposure level of blank and diabetic control mice were negligible. All the data are presented as mean $\pm \mathrm{SE}$; DM: diabetic mice. 


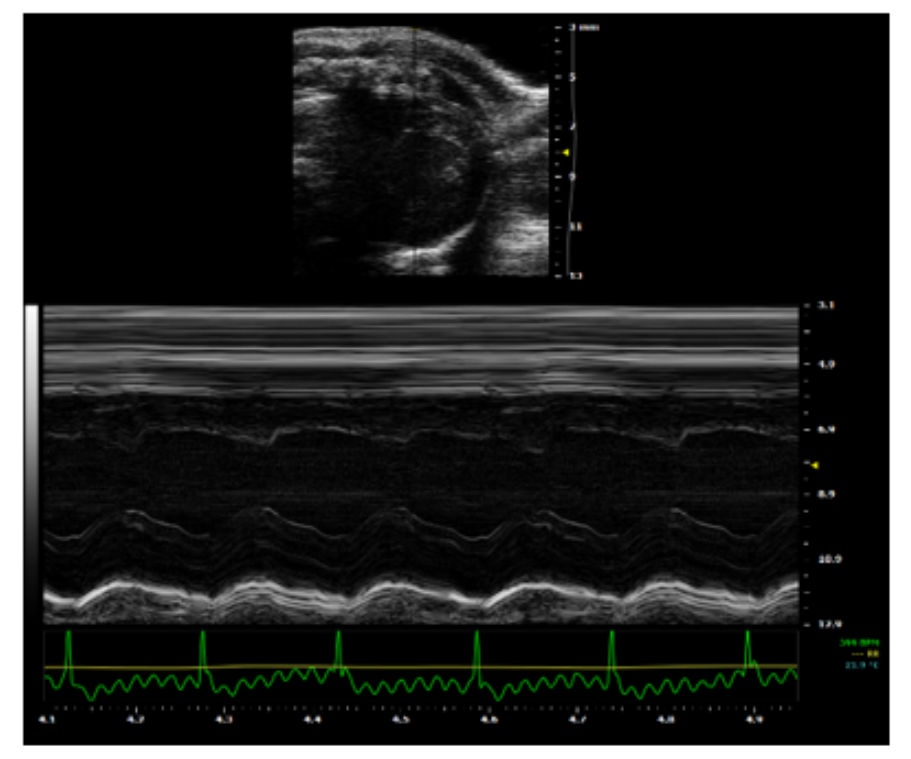

blank control

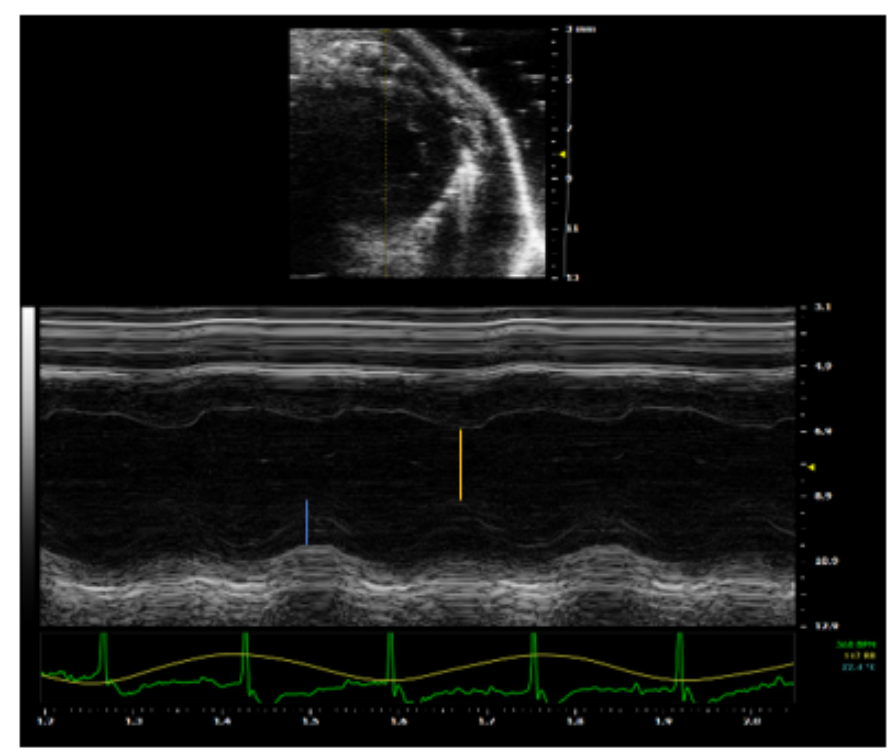

Cd Control

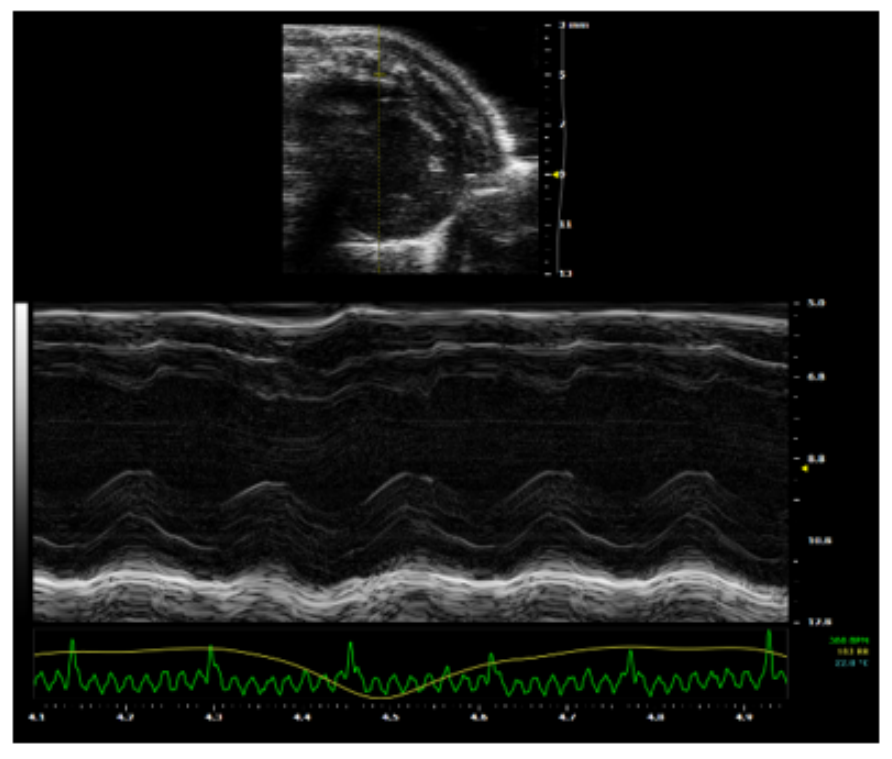

Diabetic Mice Control

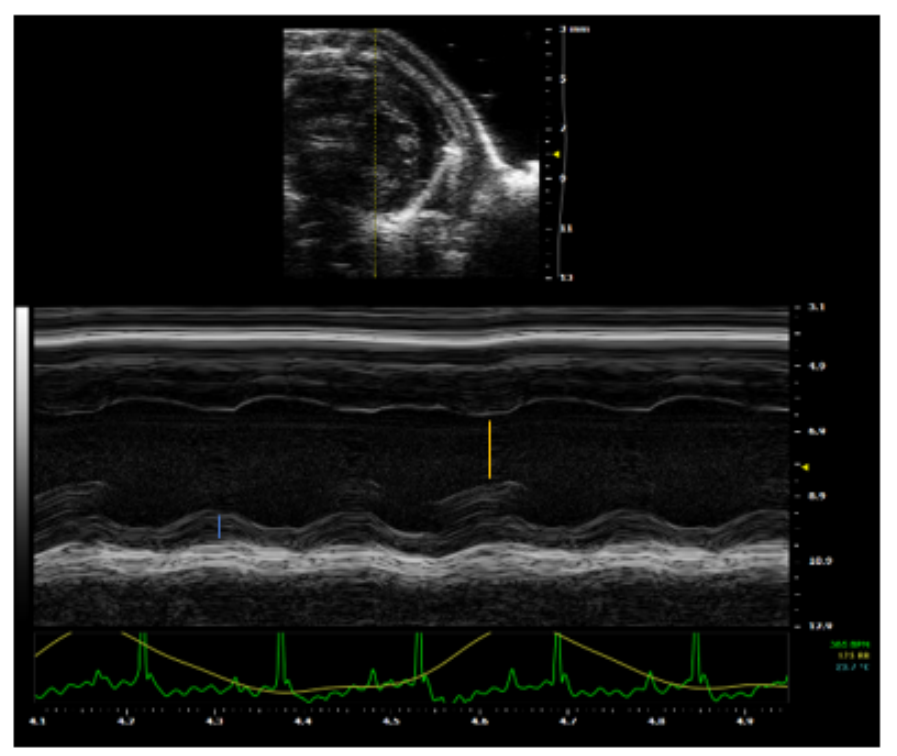

Experiment Group

Figure 2

Left ventricular echocardiographic representative images of mice in blank control, $\mathrm{Cd}$ control, diabetic mice (DM) control, experiment groups. The blue liner represents left ventricular posterior wall thickness at the end of systolic. The yellow liner represents left ventricular internal systolic diameter at the end of systolic. 
A

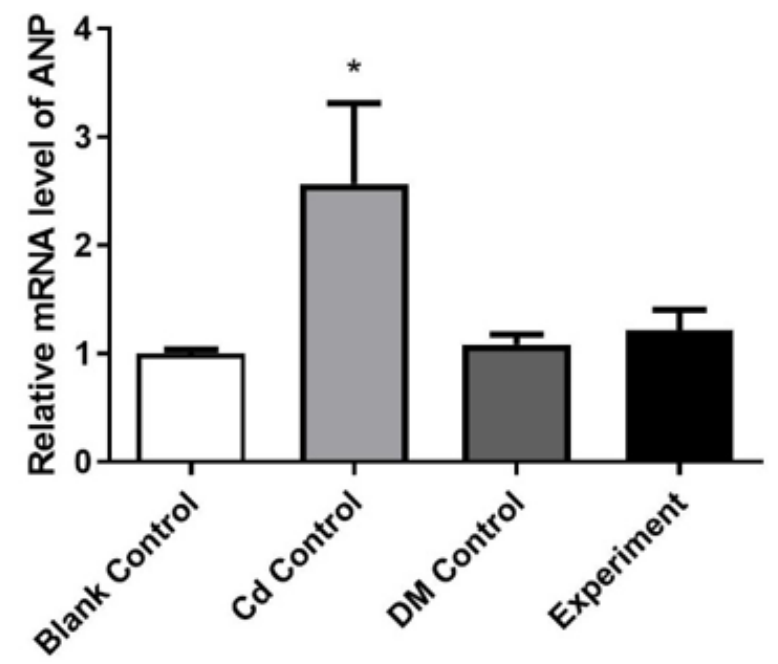

C

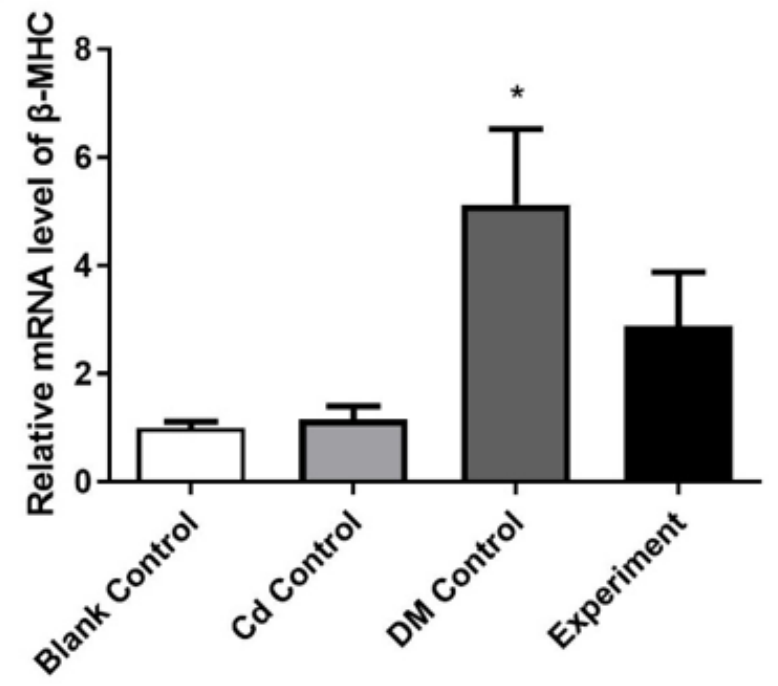

B
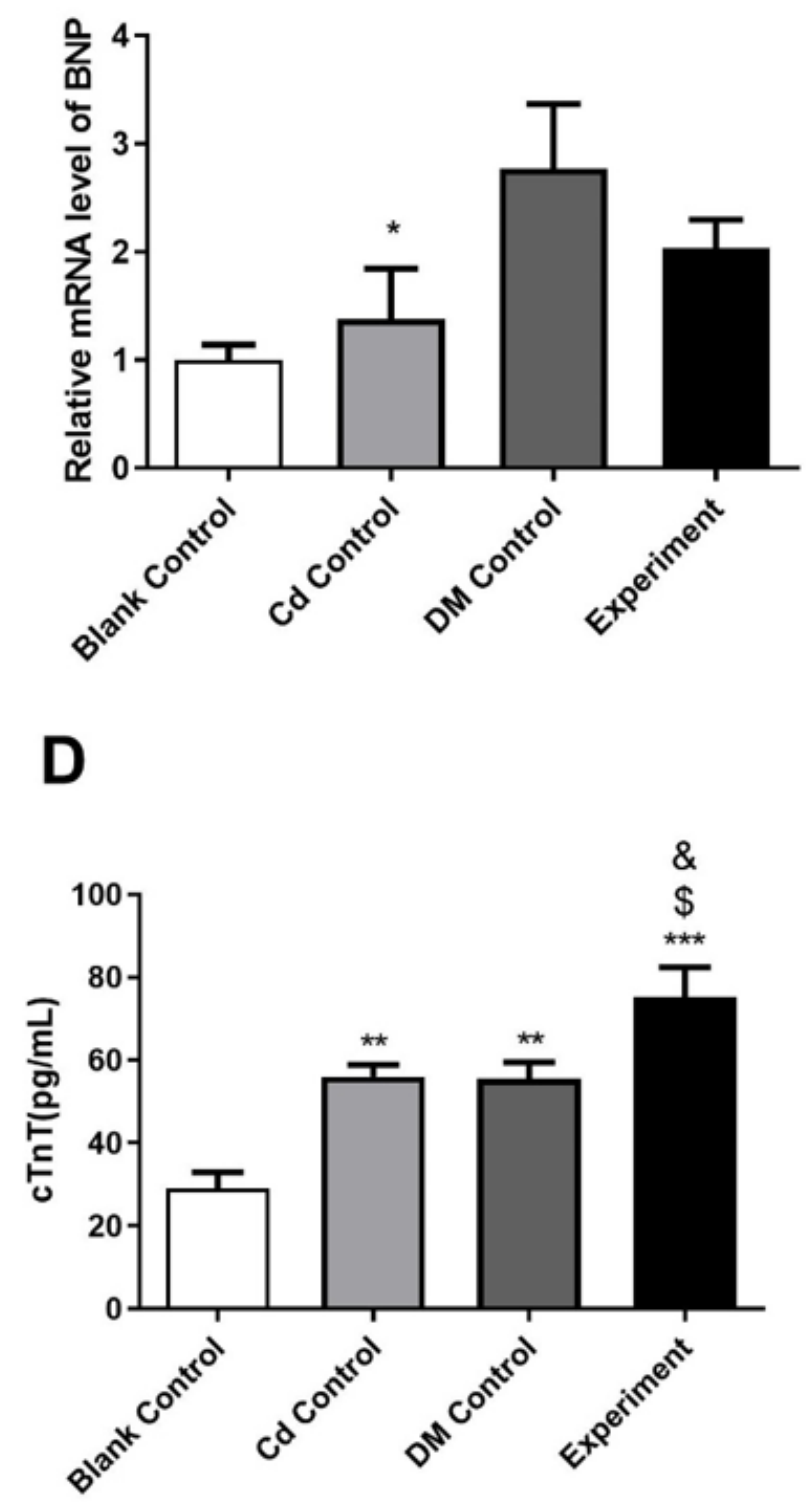

Figure 3

$\mathrm{Cd}$ aggravated the injury of cardiac tissues in diabetic mice. Expression of myocardial hypertrophy and cardiac injury genes in cardiac tissue. The ANP (A), BNP (B) and $\beta$-MHC®C levels in heart tissues was examined with qPCR. $c \operatorname{TnT}(D)$ was tested by Elisa kit. Data are presented as the mean $\pm S D$. ${ }^{*} P<0.05$, ${ }^{\star *} \mathrm{P}<0.01$, ${ }^{* \star *} \mathrm{P}<0.001$ (compared with blank control); \&P $<0.05$, \&\&P $<0.01$, \&\&\&P 0.001 (compared with Cd control); $\$ \mathrm{P}<0.05$,

$$
P<0.01,
$$

$\$ \mathrm{P}<0.001$ (compared with diabetic mice (DM) control). 

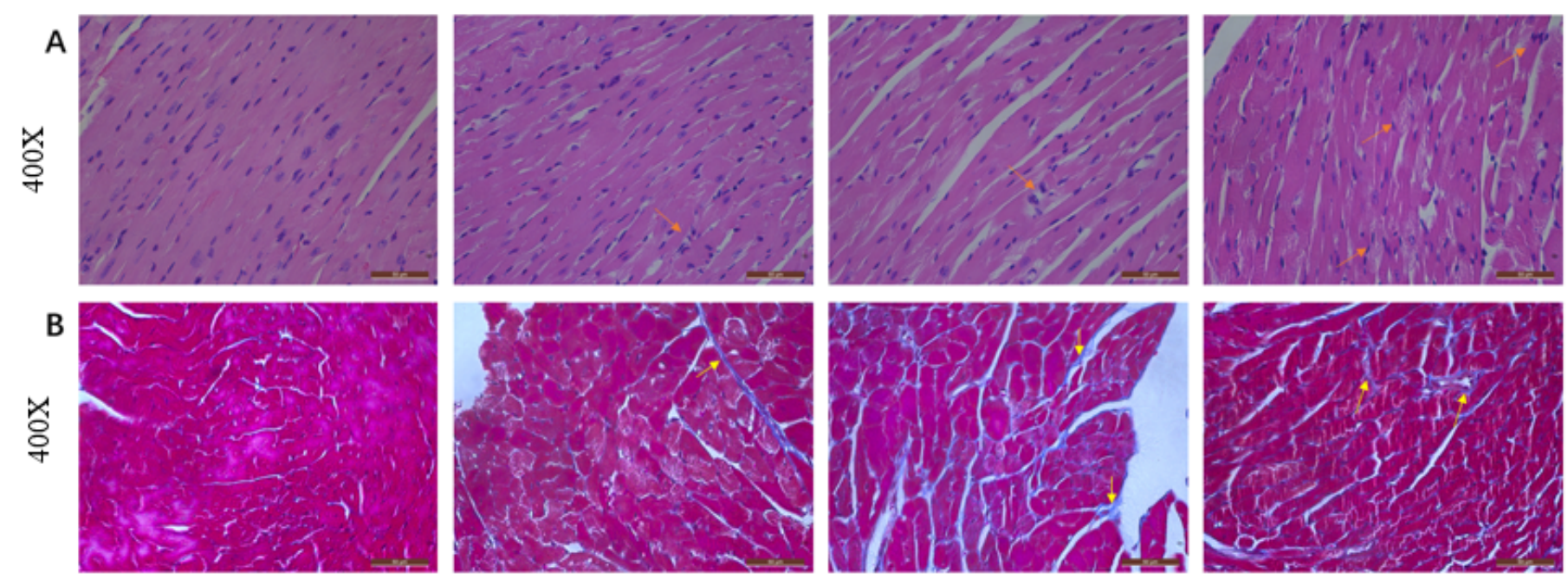

Cd Control

Diabetic Control

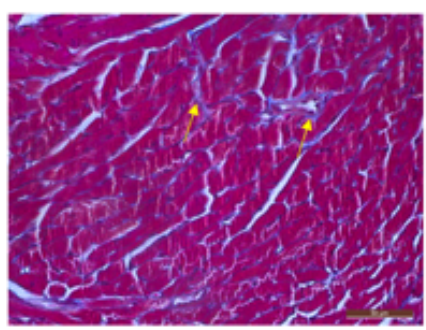

Experiment

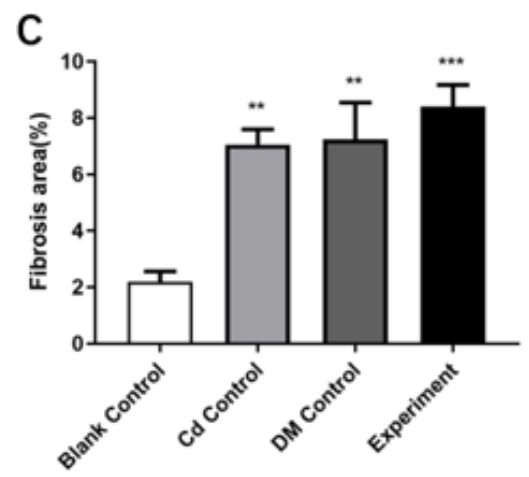

D
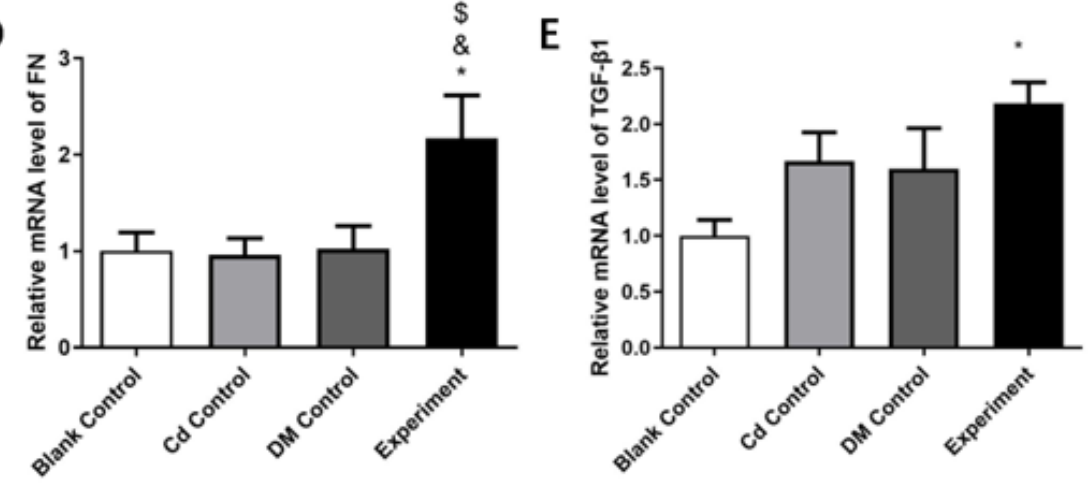

\section{Figure 4}

$\mathrm{Cd}$ increased the level of fibrosis in diabetic mice. HE staining was used to examine the damage of myocardial tissue (A). Masson staining was used to assess the collagen content of myocardial tissue ( $B$, C). Expression of fibrosis genes in cardiac tissue. The FN (D) and TGF- $\beta 1$ (E) level in heart tissues was examined with PCR. Data are presented as the mean \pm SD. P values were calculated using a one-way analysis of variance test. ${ }^{*} P<0.05,{ }^{*} \mathrm{P}<0.01,{ }^{*} * \mathrm{P}<0.001$ (compared with blank control); \&P $<0.05$, \&\&P $<0.01, \& \& \& \mathrm{P}<0.001$ (compared with Cd control); $\$ \mathrm{P}<0.05$,

$$
P<0.01
$$

$\$ \mathrm{P}<0.001$ (compared with diabetic mice (DM) control). The orange arrow represents the damaged area and yellow arrow represents the fibrosis area of heart tissues. 
A

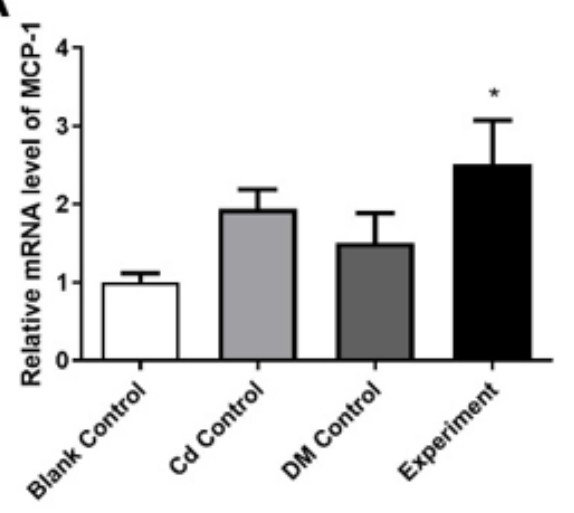

B

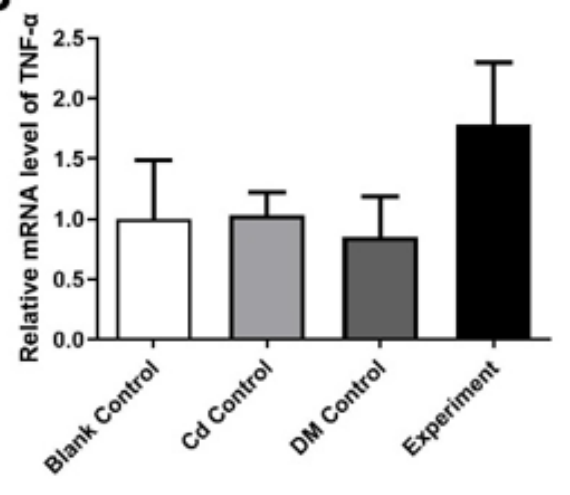

C

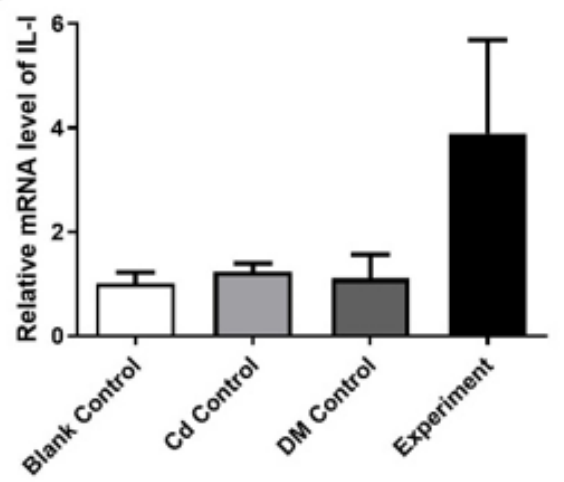

Figure 5

Cd increased the level of inflammatory cytokine in diabetic mice. Expression of inflammatory cytokine genes in cardiac tissue. The IL-1 (A), TNF-a (B) and MCP-1 (C) level in heart tissues was examined with $P C R$. Data are presented as the mean $\pm S D$. $P$ values were calculated using a one-way analysis of variance test. ${ }^{*} P<0.05$, ${ }^{\star *} P<0.01,{ }^{* \star *} P<0.001$ (compared with Con); \&P $<0.05, \& \& P<0.01, \& \& \& P<0.001$ (compared with $\mathrm{Cd}$ ); $\$ \mathrm{P}<0.05$,

$$
P<0.01
$$

$\$ \mathrm{P}<0.001$ (compared with DM); DM: diabetic mice. 